\title{
Aproximaciones y diálogos entre las traslaciones gráfica y fílmica de la obra de Roberto Bolaño
}

\section{Approximations and dialogues between graphic and film translations of the work of Roberto Bolaño}

\author{
GLORIa SEPÚlVEDa VILla \\ Universidad de Concepción (Chile) \\ gloriasepulveda@udec.cl \\ ORCID ID: 0000-0003-1688-7315
}

\begin{abstract}
Resumen: Esta propuesta de lectura busca establecer un diálogo entre las traslaciones fílmica y gráfica de las novelas Una novelita lumpen (2002) y Estrella distante (1997) de Roberto Bolaño y el film Il futuro (2013) de Alicia Scherson y Estrella distante (2018), novela gráfica de Javier Fernández y Fanny Marín (2018). La investigación establece cómo las narraciones abordan el tratamiento del relato, del mal, de lo femenino y de la política en los procesos de traslación de lo literario a lo cinematográfico y lo historietístico. El ejercicio de reapropiación por parte de los creadores audiovisuales y secuenciales permite a la obra literaria de Bolaño expandir sus significados hacia otras manifestaciones artísticas amplificando las narraciones preexistentes $y$ potenciando públicos más amplios.
\end{abstract}

Palabras clave: Adaptación fílmica, novela gráfica, mal, política, Roberto Bolaño.

\begin{abstract}
This reading proposal seeks to establish a dialogue between the filmic and graphic translations of the novels Una novelita lumpen (2002) and Estrella distante (1997) by Roberto Bolaño and the film Il futuro (2013) by Alicia Scherson and Estrella distante (2018), a graphic novel by Javier Fernández and Fanny Marín (2018). The research establishes how the narratives address the treatment of story, evil, the feminine and politics in the processes of translation from the literary to the cinematographic and the graphic narrative. The exercise of reappropriation by audiovisual and sequential creators allows Bolaño's literary work to expand its meanings to other artistic manifestations, amplifying pre-existing narratives and empowering wider audiences.
\end{abstract}

Key words:

Film adaptation, graphic novel, evil, politics, Roberto Bolaño. 


\section{INTRODUCCIÓN}

El último capítulo de La literatura nazi en América (1996) significó para Roberto Bolaño la oportunidad de dar espacio al desarrollo de uno de los personajes más inquietantes de su narrativa. En "Ramírez Hoffman, el infame" relata el auge y caída del piloto, poeta y asesino que, desde el horror, forja su proyecto poético. Un año más tarde, la editorial Anagrama publicaba Estrella distante, en donde Ramírez Hoffman evoluciona en Alberto Ruiz-Tagle, alias Carlos Wieder, poeta autodidacta e infiltrado fascista en talleres de poesía universitarios de la ciudad de Concepción.

En 2002, nuevamente bajo el sello Anagrama, Bolaño publica Una novelita lumpen. Meses después muere tras un largo padecimiento por una insuficiencia hepática. De este modo, la Novelita se convierte en su última publicación en vida. En la novela, una voz femenina relata la historia; se trata de dos hermanos que descienden a la marginalidad como un viaje ineludible de crecimiento en el que aparecen cuestionamientos a la estructura de una vida que solo es posible en los límites de lo convencionalmente correcto.

La fuerza narrativa y visual de la obra de Roberto Bolaño ha sido captada no sólo por un amplio público lector, sino que también ha interesado a distintos realizadores audiovisuales, directores teatrales y artistas de la historieta que han encontrado en su propuesta un pie forzado para llevar la letra a la pantalla, al escenario ${ }^{1}$ o a la narración gráfica. Alicia Scherson estrena Il futuro en 2013 basada en Una novelita lumpen. Finalmente, la ilustradora Fanny Marín y el guionista Javier Fernández se aventuran con la adaptación gráfica de Estrella distante en 2018 bajo la editorial Penguin Random House ${ }^{2}$.

\section{CÓMO SE ILUSTRA LA CAÍDA DE UNA ESTRELLA}

El origen de Estrella distante está vinculado a la poesía y al horror, pues uno de los protagonistas, Alberto Ruíz-Tagle, alias de Carlos Wieder, poeta y asesino, es sin duda un personaje particularísimo dentro del universo narrativo de Bolaño. Javier Fernández declaró en el diario El País su admiración por esta, la menos conocida obra del escritor: «Me gustó tanto la obra que queríamos pasar más tiempo en ese universo narrativo. Estrella distante podría tener fácilmente más de 400 páginas» (El País, 13 julio 2018). Tal como suele ser la dinámica en la producción de las novelas gráficas, se

\footnotetext{
${ }^{1} 2666$ es adaptada al teatro por Julien Gosselin en Francia y en Estados Unidos por Robert Falls, ambos en 2016.

${ }^{2}$ El gigante editorial marca una tendencia en los lanzamientos de muchas de las novelas gráficas basadas en textos hispanoamericanos que editan sus diferentes sellos, algo que se ejemplifica en Soldados de Salamina, cuyo interés de convertir la novela de Javier Cercas en «novela gráfica tuvo como intermediario y promotor a Claudio López Lamadrid, editor responsable de la división en español del holding editorial» (García-Reyes, 2020: 285).
} 
une a Fernández la ilustradora Fanny Marín, quien aporta la visualidad y la proyección icónica a la historia. En palabras de Jan Baetens: «La novela gráfica literaria toma la forma de una adaptación al igual que se puede adaptar un libro a la pantalla» (2013: 180). De este modo, Estrella distante «toma la forma de una versión ilustrada del texto original» (2013: 180) donde la novela gráfica «es una forma de narración visual» (2013: 173).

En La literatura Nazi en América (1996) Ramírez Hoffman, protagonista de uno de los relatos, es un poeta autodidacta en el taller de poesía del profesor universitario Juan Cherniakovski. En Estrella distante, Bolaño perfila al personaje como Ruiz-Tagle, quien también se trata de un poeta autodidacta que acude al taller de Juan Stein. Es posible advertir en ambos relatos cambios en ciertos momentos del discurso, aunque Bolaño decide conservar pasajes enteros en Estrella distante. En cuanto a los integrantes del taller de poesía, el narrador señala: «casi todos estudiábamos en la Facultad de Letras»; «Teníamos entre 17 y 23 años (yo tenía 18)». Las hermanas Garmendia $^{3}$ estudiaban sociología y psicología y estaba Ruiz-Tagle: «que según dijo en alguna ocasión era autodidacta» (Bolaño, 2013: 14). Pero el narrador señala que Ruiz-Tagle: «No parecía autodidacta», y más adelante agrega: «En una palabra, Ruiz-Tagle era elegante y por ese entonces no parecía que los autodidactas chilenos, siempre entre el manicomio y la desesperación, fueran elegantes» (Bolaño, 2013: 14).

Para entender esta idea de elegancia y cómo Ruiz-Tagle cuida su «imagen» recurro a lo que Jean Baudrillard propone en El crimen perfecto respecto de la sofisticación de la imagen de uno mismo: «Entregados a nuestra propia imagen, a nuestra identidad, a nuestro look, convertidos en nuestro propio objeto de atenciones, de deseo y de sufrimiento, nos hemos vuelto indiferentes a todo el resto» (1996: 177). La misteriosa elegancia de Ruiz-Tagle, que el narrador percibe de forma instantánea, oculta un sino lúgubre y horroroso que encontrará su implosión en manifestaciones como la poesía, la fotografía y el cine.

En la novela gráfica, el protagonista sueña que naufraga junto a Carlos Wieder y en ese momento comprende que su historia está íntimamente ligada a la historia de Chile. En la novela gráfica leemos: «pero no como espejo y explosión de otras historias, sino como espejo y explosión de sí misma» (Fernández y Marín, 2018: 8). Los adaptadores instalaron al autor, es decir, al alter ego de Bolaño, como el narrador protagonista que sigue, más o menos, el hilo narrativo del primer episodio situado en Concepción,

\footnotetext{
${ }^{3}$ En Ramírez Hoffman, el infame las hermanas se llaman María y Magdalena Venegas. El cambio de nombre en Estrella distante a Verónica y Angélica Garmendia parece guardar un guiño al apellido del primer rector de la Universidad de Concepción, Enrique Molina Garmendia, educador y filósofo chileno cuyo papel es fundamental en la descentralización de la educación universitaria en Chile lo que le valió los grados de Rector Fundador, Emérito y Vitalicio de la casa de estudios convertida en el escenario de los talleres de poesía de Juan Stein y Diego Soto.
} 
alrededor de 1970-71, cuando los jóvenes de diversas carreras concurren a los talleres de poesía de Juan Stein y Diego Soto.

Chile tiene a su haber cientos de ilustradores cuyos dibujos aparecían principalmente en la prensa y portadas de libros. La ilustración se afianzará en los medios a partir de la segunda mitad del siglo XX, aunque sus orígenes se remontan a La Aurora de Chile, primer periódico nacional fundando en 1812. Décadas más tarde aparecen las historietas por entrega Mampato (1968), ilustrado por Oskar y Themo Lobos y Condorito (1949), ilustrado por Pepo. En 2007, Gonzalo Martínez adapta bajo el sello Alfaguara la novela de Alberto Fuguet, Road History, bajo el mismo título, que abrirá paso en Chile a la novela gráfica como tal.

En 2009 el ilustrador Claudio Romo y el escritor Alexis Figueroa publican en LOM Informe Tunguska, que aborda la ciencia ficción desde una perspectiva política de un lugar de Chile en una dimensión paralela. Luego vendrá Quique Hache, detective, adaptada por Gonzalo Martínez en 2009 a partir de la novela juvenil de Sergio Gómez publicada en 1999. En 2015 el guionista Christian Morales y el ilustrador Luis Beto Martínez adaptan un clásico de la narrativa chilena, Hijo de Ladrón (1951) de Manuel Rojas. La complejidad narrativa de la novela sin duda debió significar un desafío para sus gestores, que optan por el blanco y negro para el apartado gráfico y donde el personaje de Aniceto Hevia toma los rasgos físicos del mismo Manuel Rojas.

Otra novela gráfica, Líneas de fuga (Toro y Gutiérrez, 2013), toma elementos de las novelas Los túneles morados (1961) y Ciudad Brumosa (1951) de Daniel Belmar y Vidas ejemplares (1990) de Sergio Gómez, entre otras obras narrativas y líricas. Roberto Bolaño aparece como personaje onírico en un loop del protagonista, un muchacho atrapado en un existencialismo decadente en una ciudad al sur del mundo. En ambos casos, tanto en Estrella distante como en Líneas de fuga, la inclusión del autor real en el relato parece generar un impacto visual que insta a significar mucho en lo narrativo puesto que el guionista se apropia de una «lectura» de los textos fuente que no tiene por qué ser aceptada por un autor que no tiene voz para cuestionar su inclusión. Para aclarar este punto, recurro a las palabras del actor chileno Alfredo Castro que, en una entrevista concedida el 24 junio de 2020 al medio El Desconcierto ${ }^{4}$, a propósito del estreno de la traslación cinematográfica de Rodrigo Sepúlveda (2020) de la novela Tengo miedo torero (2001) de Pedro Lemebel, Castro aclara que la protagonista, la loca del Frente, que él interpreta en el film, no es, por ningún motivo, Lemebel. Otro ejemplo es el tratamiento de Roberto Bolaño como personaje en la novela Soldados de Salamina (2001) de Javier Cercas, sustituido en su posterior traslación fílmica y recuperado como personaje clave en la novela gráfica (García Reyes, 2020). Bolaño aceptó el pacto ficcional en la incorporación de sí mismo en una obra, en virtud de su contacto con Cercas

\footnotetext{
${ }^{4}$ Disponible en https: //www.youtube.com/watch?v $=$ n8ABKp9Tucc\&t $=1 \mathrm{~s}$
} 
y el reconocimiento del «hibridaje» (García Reyes, 2020: 277) en la propuesta narrativa del autor español.

Como sabemos, la novela gráfica derivó de la historieta ${ }^{5}$, que tuvo gran popularidad en los lectores de periódicos. Es original de Estados Unidos y se conoce como graphic novel (Barrero, 2013), que deriva de la historieta, la novela por entregas y el comic book. De este modo, la novela gráfica se direccionó en alcanzar y promover otras concepciones de creación:

Autores como Winsor Mcay, Frank King, George Herriman y otros fueron los responsables de hallazgos estéticos que iniciaron una apertura de lo que en su momento pudo ser considerado una forma de entretenimiento plenamente legitimado por la cultura de masas para situarlo en la órbita de un leguaje experimental que aspiraba silenciosamente llegado desde otras ópticas (Trabado, 2013: 12).

En ese sentido, la traslación de la obra narrativa a lo gráfico supone una apuesta del guionista Fernández y la ilustradora Marín que, en un trabajo colaborativo, crean y/o reinventan un código textual que genera un nuevo código que invita al lector a pactar un acuerdo de experiencia estético-visual y narrativa, porque «la narrativa gráfica ofrece la posibilidad de quebrar los moldes formales y operar [...] desde afuera evadiéndose, quizá por primera vez, de los rigores del espacio» (Trabado, 2013: 13). Baetens agrega que en el campo de la novela gráfica se «acentúa el valor añadido de la colaboración creativa, en la que lo visual y lo textual interactúan de una forma abierta y no jerárquica» (2013: 174). En ese sentido, en la traslación de Estrella distante a una novela gráfica surge un subgénero por «la colaboración ${ }^{6}$ entre un artista gráfico y un guionista con un trasfondo literario» (Baetens, 2013). La crítica en torno a las novelas gráficas puede ser negativa o positiva, la primera aborda los defectos de la misma, y en la segunda «subraya las cualidades específicas y las posibilidades del género» (Baetens, 2013: 171). En este último sentido, me interesa analizar los recursos visuales propuestos por la traslación visual de Fanny Marín en la obra de Bolaño y el tratamiento del relato por Javier Fernández.

La Estrella Distante de Fernández y Marín (2018) está presentada en blanco y negro y tiene una extensión de 191 páginas, bajo el sello de la editorial Random Comic. Esta edición conserva la dedicatoria a Victoria Ávalos y a Lautaro Bolaño, la madre y el hijo del escritor, en tanto que

\footnotetext{
${ }^{5}$ Los orígenes de la historieta datan de la invención de la imprenta (siglo VIII en Oriente; siglo XV en Europa), pero cuyos antecedentes viajan en el tiempo hasta épocas remotas como el arte rupestre (35.000 A. C), los jeroglíficos (siglo IV) y los códices mayas (siglo XI).

${ }^{6}$ Un ejemplo de colaboración entre artista visual y guionista son los trabajos del ilustrador Claudio Romo y el escritor Alexis Figueroa, entre los títulos que han publicado cuentan Fragmentos de una biblioteca transparente I (2008) - II (2018), Informe Tunguska (2009) y en colaboración con otros ilustradores y con guion de Figueroa, Lota: La huelga larga del carbón (2015) y Herbolaria Memorabile (Logosedizioni, 2021).
} 


\section{Gloria Sepúlveda Villa}

Fernández y Marín incluyen una a Lourdes Domenech y a Josefina González entre sus agradecimientos. Es curioso que al ser una adaptación del texto fuente, toman a Bolaño como un autor más de la novela gráfica. Se puede especular con varios escenarios, por un lado, la imposición editorial con un marcado sentido comercial, pero en el asunto de las dedicatorias es como si los dos autores de la historieta no quisieran desprenderse de la tutela de Bolaño ni en los agradecimientos.

Cabe destacar la curatoría de las ilustraciones que presentan a la ciudad de Concepción, principal localidad del centro sur de Chile, en el primer tramo del relato, que corresponde a los primeros años de la década de los setenta. En esas viñetas se aprecia a los personajes en lugares como las calles Diagonal y Tucapel, con el edificio del mismo nombre al costado, y se advierte también otro tramo entre los viales O’Higgins y Aníbal Pinto, el conocido frontis de la Universidad de Concepción y el célebre mural pictórico Presencia de América Latina (1964-1965) del pintor mexicano Jorge González Camarena. Lugares e imágenes aún icónicas en la actualidad de «la llamada capital del Sur» (Bolaño, 2015: 13). Esto es importante, en la medida que la novela gráfica está producida por un equipo radicado en otro continente y que, probablemente, no ha visitado la ciudad. El trabajo de rastreo urbano resulta significativo cuando el narrador se refiere a esos espacios del sur de Chile como «(lugares más mentales que físicos)» (Bolaño, 2015: 16). Sirviéndose de la búsqueda digital al carecer del conocimiento penquista, hay creadores que se atreven a desplegar un espacio real que ignoran o conocen de forma muy superficial. En cierto modo es el poder de la ficción, pues el mismo Bolaño no detalla ni dispone una descripción de Concepción que al lector le permita hacerse una idea de lo que es la trama y la piel de una ciudad que ofrece aún más en los espacios que esconde, que en aquello que muestra.

Del mismo modo que en la novela original, el objetivo amoroso de los personajes circula en torno a las gemelas Garmendia, que en la novela son retratadas «altas, de piel morena y pelo negro muy largo» (Bolaño, 2015: 15). En la adaptación, optan por presentarlas con el cabello negro y rizado. Ambos relatos coinciden en que sólo Juan Stein y Ruiz-Tagle eran capaces de distinguirlas. En esta parte, la adaptación gráfica ilustra la visita de Bibiano al departamento vacío de Ruiz-Tagle, y a este, luego, en el taller de Diego Soto, donde una de las chicas, Marta Posadas, logra desentrañar con suspicacia la otra identidad de Ruiz-Tagle, el autodidacta. El episodio concluye con unas viñetas de Ruiz-Tagle y Stein, quien le comenta que sus poemas parecen escritos por otra persona, a lo que el otro responde, igual que en el texto literario: «estoy buscando» (Bolaño, 2015: 21).

Por otro lado, Fernández y Marín optimizan el relato que sigue un hilo conductor de la historia central, puesto que pese a la brevedad de la novela contiene muchas historias, dispuestas como muñecas rusas, entre la narración medular, o bien pasajes narrativos que no son considerados en la novela gráfica. $\mathrm{Al}$ optar por esta selección, se prescinde del capítulo cuatro 
en la novela gráfica en el que el narrador intenta reconstruir la historia de Juan Stein y rememora la fotografía de su tío Cherniakovski, general soviético y líder del ejército ruso durante la Segunda Guerra Mundial. A los talleristas no les agrada la foto y Stein decía que la cambiaría por una del poeta William Carlos Williams, de cuya autenticidad todos dudaban: «De todas maneras la llamaba «la foto del doctor Williams» y no se deshacía de ella» (Bolaño, 2015: 64).

Dos tópicos atraviesan la narración de Estrella Distante. Crimen y correspondencia articulan el relato en base al misterio, la muerte y la buena voluntad de un amigo. Bibiano O'Ryan es el personaje que reconstruye, epistolarmente, una memoria que el narrador complementa desde otro punto del globo.

\section{LAS FORMAS DEL FASCISMO EN LA POESÍA CIVIL}

Estrella Distante de Bolaño está cruzada por una idea central que permanece oculta. Partiendo de la obra de Roberto Arlt, Ricardo Piglia señala que «hay grandes tensiones secretas que se hacen visibles y aparecen con nitidez los puntos de fuga del imaginario social» (2001: 39). Es así cómo, en ambos relatos, el gráfico y el literario, el lector cae en la cuenta del secreto que cruza la historia central, aquello que alerta a Belano, a O'Ryan y a Martita, el secreto que se desliza en el apartamento vacío de Ruiz-Tagle, que no es otro que la sombra en la casa de las gemelas en Nacimiento. Piglia plantea que «la literatura trabaja con los límites del lenguaje, es un arte de lo implícito» (2001: 54). En la novela gráfica, la metamorfosis de Ruiz-Tagle en Wieder, también maneja el secreto y lo implícito, en tanto que ilustra al personaje sin rasgos definidos, entre sombras y fragmentado para luego ir revelándose como un siniestro poeta, acróbata del cielo, como un fotógrafo del miedo y, finalmente, como un atroz asesino.

Los personajes femeninos de los talleres de poesía, las gemelas (Verónica y Angélica), Marta Posadas y Carmen Villagrán son las únicas que entablan relaciones con Ruiz-Tagle, desde las variaciones de la amistad, el amor, el miedo y el horror. Marta le pide a Bibiano que no incluya a Ruiz-Tagle en la antología que prepara, ella comenta que revolucionará la poesía: «se sonrío como si estuviera en posesión de un gran secreto» (Bolaño, 2015: 24). En la novela gráfica leemos: «Entre los hombres, Ruiz-Tagle no hizo amigos. Nadie parecía importarle en lo más mínimo» y una ilustración de Fanny Marín que muestra al personaje de espaldas presentándolo con un aura misteriosa que manifiesta lo implícito que explosionará en las partes que siguen en el relato: «Unas horas después Alberto Ruiz-Tagle, aunque ya debería empezar a llamarle Carlos Wieder, se levanta» (2015: 31). En la novela gráfica, la transformación de Ruiz-Tagle se cierra con la luna llena alumbrando la casa de las gemelas: «Entra la noche, sale la noche. Efectiva y veloz» (Fernadéz y Marín, 2018: 39). Y los restos de una de ellas que son la prueba de que «Wieder es un hombre y no un dios» (2015: 33). Porque 
Carlos Wieder, remedo de poeta y fotógrafo, es fundamentalmente, un cruel feminicida.

En la novela y en la versión gráfica, Wieder se transforma en una «estrella» de la poesía civil. Aparece de forma espectacular cuando sus mensajes aéreos captan la atención de la prensa y las cámaras se encienden frente a él, tal como es representado en la versión gráfica, otra vez de espaldas, sosteniendo un cigarrillo y declarando: «El mayor peligro fue el silencio. El silencio es como la lepra. El silencio es como el comunismo» (Fernández y Marín, 2018: 57). Como afirma Simunovic, Wieder personifica el afán fascista declarado por miles de personas en agudos momentos de la historia, guerras mundiales, dictaduras latinoamericanas y toda forma de imposición ideológica a los pueblos: «El personaje se inspira en la configuración arquetípica del nazismo como búsqueda fundamentalista de la pureza, más allá de un humanismo decadente y romántico» (Simunovic, 2006: 15). El epígrafe que abre el relato, «Qué estrella cae sin que nadie la mire», cita de William Faulkner, nos remite al pensamiento de Guy Debord, quien en La sociedad del espectáculo propone que «la condición de estrella del espectáculo es la especialización de la vivencia aparente» (Debord, 2015: 64). Debord afirma que el espectáculo promueve la banalización que «domina mundialmente la sociedad moderna» (Ibíd.). Si hablamos de banalización, no podemos evitar vincularlo al trabajo de Hanna Arendt, quien en su ensayo Eischmann en Jerusalem (1963) dio cuenta de las estrategias del totalitarismo y de la banalización del mal. De este modo, y como ejemplo, la propaganda nazi involucraba enormes dosis de espectáculo $\mathrm{y}$, consiguientemente, de banalización.

En otro momento de la novela de Bolaño, el fascismo aparece no de la mano de Wieder, sino con el grupo de neonazis ${ }^{7}$ con los que Diego Soto, ya exiliado en París, se ve envuelto en un incidente, donde el grupo de fascistas golpea a una mujer vagabunda en la estación de tren de Perpignan: «Como el turista que Soto siempre fue desde dejó Concepción» (Bolaño, 2015: 79). En la novela gráfica, una viñeta advierte al lector de lo que sucederá con el profesor chileno; restos de sangre, un zapato y cartillas con números junto a los objetos describen escuetamente la escena de un crimen. El narrador se entera del suceso por «una carta de Bibiano, muy extensa, casi como el informe de un detective, la última que recibí de él» (2015: 80).

Después de ese episodio, en la novela gráfica aparece la historia de Lorenzo como una matrioska bolañiana en forma de relato dentro del relato. La trama de Lorenzo se explícita como un inserto ilustrado mediante otra técnica, con un dibujo infantilizado, que es un hábil y acertado recurso en la

\footnotetext{
${ }^{7}$ El neofascismo es un tema recurrente en la obra de Roberto Bolaño. Como veremos en La novelita lumpen y en la traslación cinematográfica de Il futuro, aparece en el grupo que grita «fascismo o barbarie» que a su vez remite a la obra de Domingo Faustino Sarmiento, Civilización y barbarie en las pampas argentinas (1845). En la obra de Bolaño son hordas animalizadas que carecen de empatía.
} 
narración secuencial. En ella se incluye una viñeta que alude a un efecto mise en abyme $e^{8}$, porque vemos a Belano recostado en una camilla de hospital: «Una vez cuando estaba en el hospital con el hígado destrozado, lo vi por televisión. Hacía muy bien su papel» (Fernández y Marín, 2018: 122). En la novela gráfica encontramos viñetas que aluden al papel del escritor, también escritor dentro del relato, lo que puede ser considerado como un efecto mise en abyme donde el escritor cuenta una historia al tiempo que la escribe en el mismo relato. $\mathrm{Y}$ así también aparece en la novela gráfica.

Sobre la poesía civil-espectacular de Wieder, esta se construye en base a textos latinos del libro del Génesis del Antiguo Testamento, específicamente el momento de la creación, el paso de las tinieblas a la luz. En la novela gráfica, el capítulo que ilustra el ascenso de Wieder se titula «Aprendices el fuego», un guiño a la novela de Bolaño que titula una exhibición del piloto de esa forma. Sus apariciones no solo están respaldadas por el ejército, sino también por un crítico literario con tribuna en un medio importante, que sostiene que el público se encuentra «ante el gran poeta de los nuevos tiempos» (Bolaño, 2015: 45) en voz de Ibacache, que bien puede leerse como el crítico literario Ignacio Valente, seudónimo del religioso chileno José Miguel Ibáñez Langlois.

En la novela gráfica se incluyen las divagaciones lingüísticas en torno a Wieder, sus acepciones gramaticales y semánticas. Los personajes, frente a un enigma, comienzan el proceso de investigación que desemboca en el relato mismo por medio de las cartas de Bibiano y la escritura de Belano. El punto de inflexión ocurre en la exposición fotográfica de Wieder, en que ciertas personas, entre ellas «un viejo poeta de derechas que había sido un vanguardista que tras el Golpe de Estado parecía haber recuperado los ímpetus de juventud» ${ }^{9}$ (Bolaño, 2015: 87-88). Esa medianoche el poeta y asesino fascista haría público el nuevo arte. Y la primera reacción de quien entra a la habitación y observa las fotografías es una mujer, Tatiana Von Beck, que al salir vomita. En la novela gráfica aparecen los Servicios de Inteligencia y requisan las fotografías ante la actitud férrea de Wieder, al que vemos, de nuevo representado entre sombras y reflejos: «En su última

\footnotetext{
${ }^{8}$ Lucien Dallenbach (1991) señala en El relato especular que el término mise en abyme proviene de André Gide (1891): «El hecho de que una obra de arte aparezca así trasladada, a escala de los personajes, el propio sujeto de esta obra» (apud. Dallenbach, 1991: 15). Dallenbach (1991: 15-16) agrega puntos de referencia para determinar que la mise en abyme, a grandes rasgos, «es un órgano por el que la obra se vuelve sobre sí misma; resalta la inteligibilidad y la estructura formal de la obra; constituye una realidad estructural que no es exclusiva ni del relato literatura ni de la literatura en sí».

${ }^{9}$ Bolaño juega aquí con la ambigüedad, y así como Ibacache queda asociado a Ignacio Valente, este poeta de derechas, que en la versión gráfica se multiplica, probablemente alude a Braulio Arenas, integrante del grupo surrealista Mandrágora. Arenas manifestó abiertamente su adhesión a la Junta Militar, obtuvo entre otros galardones, el Premio Nacional de Literatura en 1984.
} 
imagen pública, el teniente Wieder sostuvo un whisky en una mano que no tembló. Miraba la ciudad y la noche» (Fernández y Marín, 2018: 122).

Como afirmó Simunovic (2006), Bolaño perfila en Carlos Wieder la cara del fascismo, pues veremos que, en el relato y en la novela gráfica, cuando aparece el detective Romero ante Belano, le pide leer y analizar una considerable colección de revistas y fanzines: «Todas eran abiertamente racistas y antisemitas» (Fernández y Marín, 2018: 152), en ellas debería encontrar las pistas necesarias para llegar al asesino. En la novela y su adaptación gráfica leemos: «Es un asunto de poesía. Wieder es poeta y usted también. Ergo, para encontrar a un poeta necesito la ayuda de otro poeta» (Ibid.).

El décimo y último capítulo de la novela gráfica se titula "Epílogo para monstruos” y corresponde al número 9 en la novela de Bolaño. Después de la visita de Romero a Joanna Silvestre, el círculo va cerrándose en torno al asesino en el capítulo 8 de la novela, al tiempo que el narrador/protagonista siente la enfermedad: «Hacía tiempo que no me sentía tan bien, aunque por dentro estaba ardiendo» (Bolaño, 2015: 137). En este capítulo, el narrador descubre un grupo de escritores parisinos: los monstruos son los discípulos y discípulas de Raoul Delorme, fundador de una secta de escritores bárbaros establecida simultáneamente al ensayo revolucionario de mayo de 1968 en París. Delorme lleva a cabo lo que Wieder denominó poesía civil. En una viñeta de la novela gráfica leemos: «LA REVOLUCIÓN POR LLEGAR SERÁ DE ALGUNA MANERA LA ABOLICIÓN DE LA LITERATURA» (Fernández y Marín, 2018: 169). Wieder aparece ante el protagonista por medio de la letra, cabe decir, la lectura, tras el lente de la cámara y bajo el nombre de Jules Defoe; en el texto de Bolaño leemos: «La revolución pendiente de la literatura, venía a decir Defoe, será de alguna manera su abolición. Cuando la Poesía la hagan los no-poetas y la lean los no-lectores» (Bolaño, 2015: 143). Son uno cuantos versos los que permiten a Belano reconocer en Defoe a Wieder y los hilos de la poesía civil.

En la novela gráfica, en una de las viñetas que ilustra a Romero y Belano, antes que el último ingrese al restaurante donde identificará al exteniente, leemos que el lugar se llama, curiosamente, «El buen fin». En la novela leemos: «mírelo con cuidado y después me dice [...] piense que han pasado más de veinte años» (Bolaño, 2015: 150-151). Como buen detective, Romero tiene razón y nosotros, los lectores, sabemos que el desenlace se acerca. En este punto cabe señalar que Wieder es un ejemplo literario de lo que sucedió con cientos de miembros de las fuerzas armadas chilenas que luego de ser colaboradores del Golpe de Estado y posterior Dictadura en Chile, hicieron sus vidas con la vuelta de la Democracia y muchos de ellos viven tranquilamente. Aunque a veces son reconocidos e imprecados en la calle, se saben seguros porque nunca tendrán un juicio por los crímenes que cometieron y que siguen impunes. Por eso, en la novela, Amalia Maluenda, empleada en la casa de Nacimiento de las Garmendia, resulta tan relevante, porque ella logra llegar a juicio y su relato da cuenta de la historia de terror 
que ha vivido Chile. Wieder no asiste al juicio, pues se encuentra a miles de kilómetros viviendo con una identidad falsa.

Muchísimo se ha estudiado la presencia del mal en la obra narrativa de Roberto Bolaño. Como ejemplo, remito a los trabajos de Patricia Espinosa (2006), Alexis Candia (2010), Cristian Montes (2013), Ernesto Abundis y Anna-Lena Glesinki (2020), por nombrar acotadamente algunos de los artículos y tesis que se escriben sobre el tema en la obra del escritor. En Estrella distante, el personaje de Carlos Wieder adquiere una enorme carga de maldad en tanto que es un sujeto, aparentemente normal, capaz de llevar a cabo asesinatos sin asomo de cuestionamiento, al tiempo que convierte el mal en arte. En la novela gráfica, cuando aparece Wieder a ojos de Belano, este se presenta fragmentado: la parte superior de una cabeza, una mano sosteniendo un libro, un hombre que se ubica lejos del protagonista. El personaje se irá develando a lo largo de las viñetas, pudiendo los lectores observar a Wieder, o intuir al menos su perfil, y tras él, un cóndor y una bandera chilena: «Tenía una dureza triste irremediable. Parecía dueño de sí mismo, aunque pasara una mala racha. No parecía un poeta. No parecía un asesino de leyenda. Ni un hombre capaz de volar a la Antártica y escribir en el cielo. Ni de lejos» (Fernández y Marín, 2018: 185). Esta viñeta incorpora, como vemos, varios elementos semióticos que demarcan muchas de las características del personaje y su encarnación del fascismo civil.

En el final se observan las figuras de Romero y Belano que aparecen ensombrecidas y la última viñeta nos muestra de nuevo la cita de Faulkner con la que Bolaño abre la novela: «Qué estrella cae sin que nadie la mire» (Fernández y Marín, 2018: 190). En medio de un gran halo de luz, se distingue la sombra de Belano en una ventana e iluminada, la máquina de escribir.

\section{FILMAR IL FUTURO DE UNA NOVELITA LUMPEN}

Desde planos distintos, la novela gráfica y su lenguaje secuencial plantean un relato visual con un alto componente metafórico que expone las esencias poéticas y las virtudes narrativas del texto fuente. El tratamiento en el cine supone una multiplicación de los artífices y como se verá, la cinta de Alicia Scherson (2013) resulta totalizadora al integrar con gran detalle la estructura del texto matriz en una propuesta que persigue sus propias búsquedas a partir del sustrato matricial que genera la novela de Bolaño.

Tras este repaso a la adaptación gráfica de Fernández y Marín encontramos el trabajo de Alicia Scherson, guionista y cineasta chilena con cuatro películas bajo su dirección y otras ocho colaboraciones como guionista, que consiguió los derechos de Una novelita lumpen, gestionados por la agente literaria Carmen Ballcells, proceso anterior al boom que la obra de Bolaño desata tras su muerte en 2003. En una entrevista, Scherson declaraba que la novela «tiene lo justo y necesario. Y es tan buena que deja 


\section{Gloria Sepúlveda Villa}

el resto a la imaginación» ${ }^{10}$ (La Tercera, 19 de enero, 2013). En efecto, la novela alcanza las 151 páginas en la edición de Anagrama de 2013 y lleva en la portada ${ }^{11}$ un fotograma de Il futuro con la actriz Manuela Martelli ${ }^{12}$, que interpreta a Bianca. En la imagen sostiene una botella de leche al tiempo que mira a la cámara. Este cruce entre la obra escrita y su adaptación audiovisual permite abrir la puerta a un análisis que busca responder cuestiones en torno a la figuración de lo femenino en ambas realizaciones, mediado por el hecho de que es Scherson la que asume esa posición desde una propuesta que puede instalarse dentro de un cine feminista que reivindica la posición de la mujer y su fortaleza ante la adversidad. Por ello, intentaremos dar cuenta de un análisis semiótico-textual (José María Paz Gago, 2004) en la medida que el film lo permite, por medio de la exposición y el análisis de II futuro como traslación de Una novelita lumpen.

La Novelita lumpen está narrada a partir de la voz de su protagonista, Bianca $^{13}$. Así también en la versión cinematográfica, la actriz chilena Manuela Martelli, que ya alcanzaba los treinta años, asume el personaje de una adolescente, que junto a su hermano Tomás, interpretado por Luigi

\footnotetext{
${ }^{10}$ La frase de Scherson remite, indiscutiblemente, a la propuesta de Wolfgang Iser (1987) sobre la recepción de la obra literaria, en cuanto al texto como pura potencialidad y en su virtualidad posibilita la apropiación del mismo a partir de los «vacíos» que deberá completar el lector.

${ }^{11}$ La portada de la Colección Compactos de Anagrama es de color amarillo. La identificación cromática es alusiva a la película de Scherson, que muestra que el auto de los padres de Bianca es de color amarillo, aunque la apariencia del vehículo en el cementerio de coches hace que Bianca insista en que ese no es el automóvil de sus padres. Recuerda el color perfectamente. En efecto, no lo es y al final de la escena la cámara realiza un primer plano de un vehículo amarillo comprimido, meticulosamente inserto, como un rectángulo junto a otros, sin que los hermanos lo vean.

${ }^{12}$ Actriz y directora, su primer protagónico se produce en Be Happy (Gonzalo Justiniano, 2003) en el que interpreta a Kathy Mardovich, una niña en un contexto de alta vulnerabilidad: el padre está preso, la madre muere, su hermano homosexual la abandona e inicia una dolorosa peripecia que muestra, tempranamente, los horrores del Sename, la prostitución, la dura vida de miles de niños y niñas. Kathy es una heroína que revierte su destino para alcanzar su libertad.

${ }^{13}$ Bianca responde a la tradición literaria de personajes que ante un presente crítico se transforman súbitamente en mujeres que revolucionan cánones sociales de comportamiento femenino. Sólo para acotar, refiero a Juana Lucero (1912) de Augusto D’Halmar, a Emma Zunz (1948) de Jorge Luis Borges (1948) y Noches sin gloria (1960) de Erich Rosenrauch. En estos relatos las heroínas son expuestas a situaciones complejas de índole sexual que ponen en discusión los roles femeninos y masculinos ante el abuso y la experiencia del placer como autoconocimiento en la literatura hispanoamericana. Cabe señalar que en 1954 la película argentina Días de odio, dirigida por Leopoldo Torre Nilsson, fue la primera adaptación del cuento de Borges. Le sigue una producción franco-española, bajo la dirección de Jacquot Benoit y protagonizada por la actriz Judith Godreche en 1993, que lleva por nombre Emma Zunz.
} 
Ciardo, deben sortear las vicisitudes de la orfandad en los suburbios de Roma. Esta novela fue la última publicada en vida por Bolaño y responde a un llamado editorial.

La novela relata la metamorfosis de Bianca y su hermano Tomás, tras la muerte de sus padres en un accidente automovilístico. Sus palabras se abren con un racconto: «Ahora soy una madre y también una mujer casada, pero no hace mucho fui una delincuente» (Bolaño, 2014: 13). Bianca narra en primera persona las peripecias que se producen tras de los padres y que en la película se narran con la primera secuencia de un automóvil desplazándose «en una carretera cercana a Nápoles» (Ibíd.). Esta secuencia recoge la tragedia de manera implícita y Scherson aprovecha la preciosa luz del atardecer en el Mar Tirreno.

La versión cinematográfica contó con variados aportes para su producción y ejecución (García Reyes y Sepúlveda, 2019) y, además, Scherson se aventuró con el guion de la misma, lo que permitió darle un sello autoral propio a la representación visual de la historia, cuyos detalles no pasan desapercibidos para un espectador y lector atento. Paz Gago (2004: 221) señala que entre la literatura y el cine se producen una serie de interferencias; una de ellas es el guion: «texto híbrido de naturaleza lingüística en el que se exhiben todos los recursos cinematográficos [y es] un proceso esencial del proceso transpositivo». Por medio del guion se produce el «trasvase de un sistema esencialmente verbal a un sistema visual-verbal» (Ibíd.). A esto, Paz Gago agrega que el «guion adaptado es, pues, un paso intermedio para el caso de la transposición fílmica de una novela» (Ibíd.).

La novela de Bolaño y la adaptación de Scherson son un homenaje al cine, desde las cintas pornográficas que consume Tomás hasta los clásicos heroicos del cine péplum. Además, la novela y la película homenajean a los videoclubs, establecimientos prácticamente desaparecidos. Se trata, en resumen, de una oda al arte cinematográfico y su apreciación. Algo se subraya cuando Bianca responde al cuestionario de Donna Moderna en la novela, en concreto a la pregunta: «Si fueras una película, ¿qué película te gustaría ser?», responde: «Me gustaría ser Guerra y paz, con Audrey Hepburn y Henry Fonda. La vi hace poco en la tele» (Bolaño, 2015: 64). Esta referencia de traslación literaria al cine es un signo que evidencia el tratamiento del metarrelato inserto en la novela y en la película puesto que, como sabemos, Guerra y paz es una novela de León Tolstoi que en 1956 fue llevada al cine bajo la dirección de King Vidor ${ }^{14}$.

Cuando José María Paz Gago (2004) estudia la relación dinámica entre cine y literatura y los diversos aportes teóricos y metodológicos de quienes han contribuido al análisis de los trasvases fílmicos literarios, agrega que los estudios tienden a valorar las obras desde un punto de vista subjetivo, desviándose del análisis científico. Por lo anterior, propone que «la novela

\footnotetext{
${ }^{14}$ Posteriormente, en 1966 la Unión Soviética filmará una versión entregada en cuatro partes con dirección de Serguei Bondarchuk.
} 


\section{Gloria Sepúlveda Villa}

y el filme tienen en común dos rasgos definitorios esenciales: la narratividad y la ficcionalidad» (Paz Gago, 2004: 206) ${ }^{15}$. En el caso del trasvase que aquí exponemos abordamos una obra literaria que, por medio del guion ${ }^{16}$, «cuenta» la historia original con imágenes y sonido. Para contar la historia, la directora y guionista (Scherson) presta atención a una serie de detalles que le permiten configurar el ambiente escenográfico en el que se insertan los personajes. Un ejemplo: cuando Bianca y su hermano retiran lo que ha quedado del auto de sus padres, el encargado le entrega un reloj que, milagrosamente, aún funciona. Este detalle opera como un signo de tiempo cuya característica principal es ir hacia adelante, nunca hacia atrás, característica que, a pesar de la remembranza de las dos narraciones, novela y film, marca la voluntad de Bianca de ir y mirar hacia el futuro. En la misma línea sigue la pregunta de la asistente social que, aparentemente, sigue a los hermanos. Respecto a lo que estudiarán, Tomás responde que informática, a lo que la asistente le dice que es una carrera con «futuro», en tanto que Bianca no lo sabe y está por salir del instituto.

No obstante, los hermanos carecen de toda orientación o tutelas adultas. El suyo es un camino marcado por la experiencia. Otro signo de tiempo viene marcado por el tatuaje de la asistente «AD ASTRA PER ASPERA», aforismo latino que se traduce como «a las estrellas por el camino más difícil». En el mismo sentido, resulta esclarecedor el tatuaje del boloñés «la mia anima non muore in questa spirale» (García Reyes y Sepúlveda Villa, 2019) cuya traducción estimada al español sería: «mi alma no muere en esta espiral», puesto que, como han probado estudios recientes de astronomía, el movimiento de los astros es en espiral y hacia delante. Scherson se vale del futuro en tanto signo temporal que recorre la novela y se traslada en la narración cinematográfica, común en ambas narraciones en la peripecia de Bianca y su metamorfosis vital, porque como propuso Ernst Bloch, la esperanza está en el futuro.

La transformación como premisa presenta otros signos que están dados por el manejo de la luz, algo que se evidencia en la novela y que, en la película, se representa en la luminiscencia del cuerpo de Bianca: «Entonces me miré en el espejo y me vi ojerosa, con la piel blanca, como si la luna, que para mí brillaba tanto como el sol, me estuviera afectando» (Bolaño, 2014: 47), alusión a la inversión de la noche en día y las tormentas solares.

\footnotetext{
${ }^{15}$ El artículo cita los aportes fundamentales de Käte Hamburguer (1995), quien en su libro La lógica de la literatura, señala que la teoría de la literatura es fenomenológica. Hamburguer propone que la lógica de la literatura «tiene por objeto la relación de la literatura con el sistema general del lenguaje» (en cursiva en el original, 1995: 10). Hamburguer agrega que: «el cine como tal no forma parte del ámbito de las artes figurativas, sino de las literarias» (1995: 149). En este sentido, se abren los estudios en torno a la literatura y sus dinámicas con otros lenguajes, como son los casos que analizamos.

${ }^{16}$ «La configuración del guion incorpora aristas como la visualidad, la planificación, acciones, diálogo, etc.» (Paz Gago, 2004: 222).
} 
Por otro lado, la incorporación de la educación pornográfica parece revelar a la joven un extrañamiento en torno al ejercicio sexual. Ese distanciamiento le permite ejercer el poder en torno al acceso de su intimidad, al parecer un objeto de deseo para el libio y el boloñés. El poder sobre sí mismo se enfrenta al poder de los sistemas en la consigna «fascismo o barbarie» (Bolaño, 2014: 27), que revela implícitamente a la protagonista un conocimiento de las dinámicas del poder en el espacio público y en el ámbito de lo privado. En la novela, los fascistas se movilizan en un vehículo, en tanto que en la película es un grupo a pie; ellos no ven a Bianca, y en la novela la chica no los mira: «Yo miraba las aguas del río y las carátulas de mis películas y trataba de olvidar las pocas cosas que sabía» (Ibíd.)

El libio y el boloñés, seres marginales que se mueven en el lumpen, traman robar a Maciste, una estrella del cine péplum que está ciega. Les cuentan el plan a los hermanos, pero es Bianca la pieza clave. Entre los réditos que les traería la consecución de su robo, mencionan que sería «el golpe perfecto que nos abriría a los cuatro las puertas de una vida nueva, una casa cerca de la playa, por ejemplo, un restaurante en Tánger, un gimnasio en el norte» (Bolaño, 2014: 79). En un espacio como el romano, tan italiano per se y al tiempo cercano a Bolaño, Scherson incorpora algunos guiños a Chile, como la anécdota en relación a los parientes que Bianca no quiere contactar y la casa en el «mar en Chile» que sugiere el boloñés cuando le habla del plan de Maciste. En la película, Bianca habla idiomas, lo que presenta una ventaja respecto al libio y al boloñés, pues no poseen la capacidad de comunicarse en lengua inglesa con la estrella cinematográfica caída en desgracia. Por supuesto, el plan tiene un «piccolo sacrificio» ${ }^{17}$ que conlleva una prestación sexual de la protagonista. Después del primer encuentro con Maciste, Bianca advierte el comienzo de su transformación: «Estoy cambiando, estoy cambiando» dice al tiempo que camina por la ciudad. En este sentido, resultan fundamentales las palabras del director Fernando Trueba recogidas por Paz Gago cuando afirma que «el cine es Literatura, es un texto que se escribe con imágenes y sonido, rostros y palabras, cuerpos, gestos, emoción y movimiento, luz y silencio sobre un papel hecho de tiempo» (2004: 225).

\footnotetext{
17 Bianca comparte con otras heroínas literarias como Emma Zunz (Jorge Luis Borges, 1944) y Lucy (Noches sin gloria, Erich Rosenrauch, 1961) el encuentro sexual como un medio para la consecución de conocimiento. Michel Foucault lo explica en Historia de la sexualidad (1986) donde la problematización de la misma invita a los seres humanos a un «arte de existencia» (1986: 14), es decir, «modificarse en su ser singular y hacer de su vida una obra que presenta ciertos valores estéticos y responde a ciertos criterios de estilo» (Borges, 1986: 14). De este modo, Emma sabe que el hombre «fue un instrumento» (Borges, 2014: 76) y Lucy utiliza las variaciones musicales para conocerse y gozar de sí: «en cuanto al sexo mismo, prestaba a sus planes un apoyo que dependía de la representación mental que de él se hiciera en el instante de darle los usos acostumbrados» (Rosenrauch, 1961: 53).
} 


\section{Gloria Sepúlveda Villa}

El tratamiento de la relación que Bianca entabla con Maciste está tratada desde la memoria de una intimidad que en la película aparece con el masaje que el otrora Mister Universe da a la muchacha. La primera noche, él le ofrece un sándwich que ella rechaza, no así la comida que preparan el libio y el boloñés. La noche siguiente, Bianca acepta el bocadillo, abriéndose a compartir y conversar con Maciste. Es más, la directora se permite la licencia de mostrar a Bianca comiendo directamente del racimo las uvas en la cocina de Maciste. Un gesto que puede considerarse exagerado si el otro personaje es ciego, pero los planos y el tratamiento de la luz lo ameritan. En la novela, el lector sabrá que Maciste es en realidad «Giovanni Dellacroce» (Bolaño, 2014: 103), Míster Italia, Míster Europa y Míster Universo, italiano, actor que «a veces había sido el bueno de la película y otras veces, al final, el malo, porque eso es la ley de la vida» (Bolaño, 2014: 103).

En la versión de Scherson se dice que puede ser australiano o inglés y su nombre es «Reg Morris». En la novela y la película transitan diversos imaginarios de la de la cultura pop y el lumpen, cuya acepción original proviene del alemán y refiere al lumpenproletiarat, la condición que congrega a las capas sociales marginales que no cuentan con recursos económicos, como la protagonista que ante la orfandad ingresa, en un descenso a los infiernos, en la delincuencia y triunfa a pesar de sí misma cuando toma conciencia de que posee «un poder casi sobrenatural, llegué a pensar alguna vez (aunque acto seguido me burlaba de estos pensamientos), que obligaba a callar a seres de común charlatanes [...] sabiendo por qué las cosas están donde están, con un grado de lucidez que ya no he vuelto a poseer» (Bolaño, 2014: 123). La muerte de los padres trastoca a la niña convirtiéndola en una mujer, aparentemente sin escrúpulos, que juega con su destino al involucrarse con Maciste, «pero donde mi destino por primera vez era completamente mío» (Bolaño, 2014: 131).

El tratamiento de la historia fílmica incluye escenas que no están narradas en la novela, pero con habilidad la directora y guionista los encaja a su propuesta amplificando temática y estéticamente el texto fuente; un ejemplo de ello es la segunda visita de la asistente social al departamento de los hermanos. El espectador observa que el lugar no está reluciente como antes y se percibe que las relaciones entre el libio, el boloñés y Bianca se tensan porque no hay botín. Cuando la asistente sale de la casa, Bianca observa desde la ventana que la mujer ha sido atropellada por un ciclista, el plano es completo y los papeles que llevaba, signo de la burocracia, se van con el viento. Otro ejemplo es cuando Bianca le confiesa a Maciste que se ha enamorado y él responde: «Don't be silly». En el taxi de vuelta a los suburbios de Roma, las silenciosas lágrimas de la chica reflejadas en la ventana dan cuenta de su honda soledad.

Otra escena proyectada por Scherson es el concurso ficticio de fisicoculturismo que resulta un fracaso porque Gigi, a quien entrenaron el libio y el boloñés, supuestamente incluye música considerada «gay» en su 
presentación, restándole profesionalismo. Otro ejemplo es la noche que Maciste duerme con dificultad por la fiebre y la muchacha recorre la casa sin éxito buscando la caja fuerte con dinero de Maciste, buscando algo de valor. En una de las habitaciones hay dos cuadros, uno es un retrato de Maciste como Míster Universo y en el otro está vestido con un traje a rayas, sosteniendo un cigarrillo. Un espectador atento verá una perspectiva mise en abyme porque detrás de la figura del segundo cuadro, hay un pequeño cuadro que reproduce la primera pintura. De este modo, estos incisos crean un ambiente y desarrollan notablemente los sentidos del relato en la propuesta del film.

La perspectiva en mise en abyme también aparece cuando Bianca camina frente al gigante cinematográfico Cinecittá, un complejo que reúne estudios de cine y televisión en los que se han rodado más de 3.000 películas. Frederico Fellini se refirió a ella como «la fábrica de los sueños». Allí se filmó Cleopatra (Joseph Leo Mankiewicz, 1963), Quo Vadis? (Mervyn Leroy, 1951), Ben Hur (William Wyler, 1951), entre otras películas. Desde esta perspectiva, Maciste, en su calidad de actor de películas de temas grecolatinos, se convierte en un guiño a la edad dorada del cine, al mismo tiempo que Scherson muestra cómo se filma dentro del film.

\section{CONCLUSIONES}

Las traslaciones de Estrella distante y Una novelita lumpen suponen un salto cualitativo de los textos bolañianos a otros soportes y su importancia se cifra en una expansión de los mundos ficcionales del escritor y en la ampliación de los potenciales lectores y espectadores que, a partir de la historieta o el cine, se acercan al universo narrativo del escritor. Tanto la novela gráfica como el film reescriben los relatos por medio de la visualidad ampliando los sentidos de la obra original y articulando nuevos relatos a partir de los textos fuentes del escritor.

$\mathrm{Al}$ pensar en la novela gráfica y su evolución desde el cómic, se pone de manifiesto la discusión entre los límites y dinámicas de la literalidad y visualidad, al tiempo que, por medio de la ilustración, da rostro a los personajes de ficción materializando una configuración óptica de los relatos literarios, condicionante que Iser consideraba funesta en la experiencia lectora, pero que cualitativamente nos permite indagar en el valor de la representación y en los dispositivos que se activan en la elaboración de una narración a partir de otra, abriendo la discusión a los sentidos y los significados de la obra que trasvasa.

El largometraje de Scherson permite amplificar estéticamente los escenarios de la novela y desarrolla física y emocionalmente el mundo interior de la protagonista que, como otras heroínas literarias y cinematográficas, realizando una inmersión en el peligro se alza triunfante sobre las dificultades que se le presentan.

En 2014 la cadena de televisión estadounidense HBO emitió la primera temporada de la serie de intriga policial True detective con los actores 


\section{Gloria Sepúlveda Villa}

Matthew McConaughey y Woody Harrelson en los protagónicos. El guionista, Nic Pizzolatto, mencionó en True detective: Antología de lecturas no obligatorias (Errata Naturae, 2014) que la novela 2666 influyó en las peripecias de Rust Cohle y Martin Harr, declarándose como un lector voraz del trabajo de Roberto Bolaño. Quienes vieron la serie podrán intuir la influencia de la parte de Fate y los crímenes en la producción audiovisual dirigida por Cary Fukunaga. Años más tarde, el escritor y guionista chileno Simón Soto declaró que basó su trabajo de escritura de la serie para televisión La frontera en True Detective que a su vez fue inspirada por 2666: «Dije hay que hacer un True Detective en la Araucanía, o tomar ese ADN con este conflicto tan poderoso» (Simón Soto en el suplemento Culto del diario La Tercera, 21 de junio de 2019).

Como vemos, la obra de Roberto Bolaño posee elementos narrativos visuales muy interesantes y continuará expandiéndose a otros formatos. Los trasvases aquí tratados dan cuenta de las diversas posibilidades del lenguaje narrativo que configura nuevas formas de narrar un texto fuente ampliando la estética del mismo a nuevos soportes mediales. Por lo anterior, resultaría interesante abordar la adaptación teatral de 2666 de Julien Gosselin que dura nada menos que 12 horas y fue estrenada en 2016 en el Festival de Teatro de Aviñón. El mismo año, el director Robert Falls, gracias al aporte monetario del actor Roy Cockrum, llevó a las tablas con la compañía Teatro Goodman de Chicago la novela de Bolaño en un montaje que alcanzó 5 horas de duración. Debido a la complejidad narrativa de la 2666 y sus adaptaciones al teatro, esta investigación se ocupó de las traslaciones de Estrella Distante y Una novelita lumpen para favorecer el equilibrio del análisis propuesto con la esperanza de abordar, a partir de un acercamiento crítico, las adaptaciones de 2666 en otro artículo en el futuro.

En estas perspectivas de estudio, resulta muy procedente apreciar la obra narrativa de Roberto Bolaño como una fuente privilegiada e inagotable de recursos que se pueden materializar en creaciones visuales y audiovisuales abordadas desde la narración gráfica y el cine tal como han explorado Alicia Scherson, Fanny Marín y Javier Fernández en sus respectivas traslaciones de la obra literaria de Bolaño.

\section{BIBLIOGRAFÍA CITADA}

BAETENS, Jan (2013), «Novelas gráficas: ¿literatura sin texto?», en J. M. Trabado (comp.), La novela gráfica. Poéticas y modelos narrativos, Madrid, Arco/Libros, págs. 169-187.

BAUDRILlaRD, Jean (1996), El crimen perfecto, trad. de Joaquín Jordá, Barcelona, Anagrama.

BOLAÑo, Roberto (1996), La literatura nazi en América, Barcelona, Anagrama.

Bolaño, Roberto (1996), Estrella distante, Barcelona, Anagrama.

BOLAÑO, Roberto (2014), Una novelita lumpen, Barcelona, Anagrama. 
Borges, Jorge Luis (2014), El Aleph, Santiago, DeBolsillo.

Castro, Alfredo (2020), \#ConversacionesEnCasa con Alfredo Castro. El Desconcierto. [En línea https://www.youtube.com/watch?v=n8ABKp9Tucc/ Fecha de consulta $11 / 10 / 2020]$.

Debord, Guy. (2015), La sociedad del espectáculo, trad. de José Luis Pardo, Valencia, Pre-Textos.

DallenbaCh, Lucien (1991), El relato especular, trad. de Ramón Buenaventura, Madrid, Visor.

FOUCAult, Michel (1986), Historia de la sexualidad 2. El uso de los placeres, trad. de Martí Soler, México, Siglo XXI.

García Reyes, David (2020), «Reescrituras en Soldados de Salamina o Las sendas de la memoria: Desplazamientos de la literatura en el cine y en la narración figurativa», Trasvases entre la literatura y el cine, 2, págs. 271291.

García Reyes, David y Sepúlveda, Gloria (2019), «De la "novelita” a "Il futuro". Lecturas bolañianas en clave trasnacional», Archivos de la filmoteca, 0/77, 2019, págs. 177-196.

GONZÁlEZ, Rodrigo (2013), «El futuro. La triste crónica romana de Alicia Scherson sobre Bolaño. La Tercera. [En línea: http://ibermediadigital.com/ibermedia-television/el-futuro-latriste-cronica-romana-de-alicia-scherson-sobre-bolano/ Fecha de consulta: 15/11/2020].

Hamburguer, Käte (1995), La lógica de la literatura, trad. de José Luis Arántegui, Madrid, Visor.

ISER, Wolfgang (1987), El acto de leer. Teoría del efecto estético, trad. de Manuel Barbeito, México, Taurus.

Merino, Sofía (2018), «Una carta de amor a Roberto Bolaño», El País, s. pág. [En línea: https://elpais.com/cultura/2018/07/12/actualidad/1531399744_2 05465.html Fecha de consulta: 20/11/2020].

Paz Gago, José María (2004), «Propuestas para un replanteamiento metodológico en el estudio de las relaciones de literatura y cine. El método comparativo semiótico-textual», Signa, 3, págs. 199- 232.

Piglia, Ricardo (2006), Crítica y ficción, Barcelona, Anagrama.

Rosenrauch, Erich (1961), Noches sin gloria, Santiago, Editorial Del Pacífico.

SCHERSON, Alicia (2013), Il futuro, prod. Chile, Italia, Alemania, España. $92 \mathrm{~min}$.

Simunovic, Horacio (2006), «Estrella distante: Crimen y poesía», Acta literaria,33, págs. 9-25.

Soto, Simón (2019), «Un True Detective en La Araucanía: así es la serie chilena ambientada en el conflicto mapuche», La Tercera, 21 de junio.

[En línea: https://www.latercera.com/culto/2020/06/24/un-true- 


\section{Gloria Sepúlveda Villa}

detective-en-la-araucania-asi-es-la-serie-chilena-ambientada-en-elconflicto-mapuche/. Fecha de consulta 01/05/2021].

Trabado, José Manuel (2013), «La novela gráfica en el laberinto de los formatos del cómic», en J. M. Trabado (comp.), La novela gráfica. Poéticas y modelos narrativos, Madrid, Arco/Libros, págs. 11- 61.

Fecha de recepción: 09/02/21.

Fecha de aceptación: 08/05/21. 